\title{
Determination of Sagittal Skeletal Discrepancy through Beta Angle: A Lateral Cephalometric Study
}

\author{
Dr. Farah Saleem', Dr. Zubair H. Awiasi² \\ 'Post Graduate Resident \\ ${ }^{2}$ Associate Professor and Head of Department \\ Department of Orthodontics, Nishtar Institute of Dentistry, Multan, Pakistan
}

Corresponding author: Dr Farah Saleem, Email: farahsaleem117@gmail.com

\section{ABSTRACT}

Introduction: Accurate classification and treatment planning relies on correct diagnosis of skeletal and dental relationships. Commonly used measurements used to classify sagittal relationship ANB and Wit's appraisal are not without potential inherent problems which might lead to less accurate classification of sagittal dysplasia. To avoid these problems, a new approach Beta angle was introduced by Baik in 2004. Beta angle as it involves different landmarks of classifying anterior-posterior relationships is said to be devoid of those problems thus more reliable. We conducted a cross sectional study to measure the angle among patients presenting in Nishtar Institute of Dentistry Multan Pakistan.

Materials and Method: Ninety pretreatment cephalometric x-rays of patients between ages 12 to 30 years were selected and studied. They were divided into three classes based on ANB angle and Wit's appraisal. For the measurement of Beta angle, a line was drawn from the center of condyle (C) to point $A$ and other to point $B$. A third line joining $A$ to $B$ was drawn. A line from point $A$ perpendicular to line $C-B$ was drawn and angle was measured between this perpendicular and line joining A-B. ANOVA was used to compare means of three groups. Pearson correlational coefficient was used to correlate relationship between Beta angle and ANB angle.

Result: The results showed Beta angle ranged between $27^{\circ}$ and $34^{\circ}$ for class I. Subjects having angle less than $27^{\circ}$ can be classified as skeletal class II and those with angles larger than $34^{\circ}$ as skeletal class III subjects.

Conclusion: Beta angle is reliable method for assessing and classifying sagittal skeletal discrepancies.

KEYWORDS: Beta angle, Cephalometrics, Sagittal discrepancies

\section{INTRODUCTION}

Ever since its invention, cephalometrics have under gone a tremendous change during its course. From diagnosis to classification, treatment planning and prognosis cephalometrics plays a key role in treatment of orthodontic patients and have stood test of time. Over the time a lot of analyses have been introduced and used by clinicians for diagnosis of skeletal and dental discrepancies. In spite of a number of analyses available and under use, the yardstick of rendering sagittal dysplasia with utmost accuracy remains missing. After Down's ${ }^{1}$ description of points $A$ and $B$, Reidel $^{2,3}$ introduced ANB angle that has been in use for decades but still has got problems of its own naming the angle being altered by position of both Nasion ${ }^{4}$ and rotation of jaws, making it a good but not ultimate choice for the classification of skeletal problems ${ }^{5,6}$. Wit's appraisal ${ }^{7,8}$ presented by Jacobson in 1970's is also a way of adding reliability to ANB angle and evaluating sagittal discrepancy as this relates to maxilla and mandible to functional occlusal plane. But as with the case of ANB angle this too is prone to error owing to the drawing of correct functional occlusal plane needed to take this measurement ${ }^{9-10}$. Use of both of ANB and Witt's appraisal in conjunction with each other has remained as method of choice for classifying sagittal dysplasia. However, problem of parameter of choice occurs if they both show different values. 
Many authors have devised new approaches to overcome these problems A novel approach to determine correct sagittal relationship is Beta angle proposed by Baik ${ }^{11}$ in 2004. Beta angle is not dependent on cranial landmarks and planes. Along with this, the angle is said to remain fairly constant even if jaw rotates making it a better and more reliable predictor of anteroposterior relationships. Since the norms of various analyses varies among different population groups ${ }^{12}$ it would be wise to carry out a separate study that determines more suitable norms for a specific population group. The purpose of this cross sectional study was to evaluate the reliability of Beta angle in assessing the sagittal relationship and to find out mean value of Beta angle among South Punjab population in Pakistan.

\section{MATERIALS AND METHOD}

Pretreatment cephalograms of patients undergoing orthodontic treatment in department of Orthodontics, Nishtar Institute of Dentistry, Multan, were studied for this study. A total of 120 files were evaluated out of which 90 cephalograms were found to be suited to carry out study. The inclusion criteria consisted of patients with ages 12 to 30 years with no previous history of orthodontic treatment. All cephalograms were traced for ANB, Beta angle and Wit's values by two investigators separately and a mean value was taken for each measurement.

Patients were divided into three groups based on ANB and Wit's appraisal among skeletal class I II and III as follows:

\section{Skeletal Class I:}

ANB angle of $1^{\circ}-4^{\circ}$

Wit's value of $-1 \mathrm{~mm}$ for males and $0 \mathrm{~mm}$ for females will be classified as having skeletal class I

Skeletal Class II:

ANB angle of greater than $4^{\circ}$

Wit's $A O$ ahead of $B O$ will be classified as having skeletal class II

\section{Skeletal Class III:}

ANB angle of $0^{\circ}$ or less

Wit's $\mathrm{BO}$ ahead of $\mathrm{AO}$ will be classified as having skeletal class III

Beta angle as described by Baik, as shown in figure 1, was taken as follows ${ }^{11}$

Point A: Deepest point in maxilla

Point B: Deepest point in mandible
Pont C: Center of condyle (drawing condyle and taking approximate center)

Draw first line from point $\mathrm{C}$ to $\mathrm{A}$

Draw another line connecting points $C$ and $B$.

Draw a third line joining points $A$ and $B$

Next, draw perpendicular from point A on line B-C.

Beta angle is measured as angle forming between this perpendicular line and line A-B line. (Figure 1)

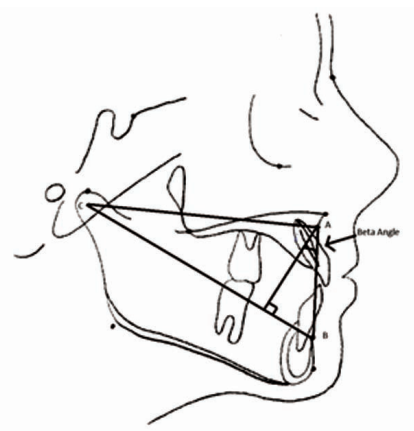

Figure 1: Measurements taken for Beta Angle.

\section{Statistical analysis}

All data collected was entered, checked and analyzed in SPSS 20.0. Mean of each group was calculated and one way ANOVA followed by post hoc Tuckey test was applied. $p$ value of $\leq 0.05$ was used as statistically significant (Table 1 ). Pearson correlational coefficient was used to correlate ANB and Beta angle (Table 2).

\section{RESULT}

Ninety pretreatment cephalograms were studied. For skeletal class I, mean Beta angle was $30.9^{\circ} \pm 3.4^{\circ}$ (Female : $31.6^{\circ} \pm 3.6^{\circ}$ and Male: $29.75^{\circ} \pm 2.7^{\circ}$ ). For class II mean angle was $25.08^{\circ} \pm 3.6^{\circ}$ (Females : $25.03^{\circ} \pm 3.3^{\circ}$ and in Males $25.16^{\circ} \pm 4.2^{\circ}$ ). For skeletal class III mean Beta angle was found to be $40.2^{\circ} \pm 5$. (Females : $39.4^{\circ} \pm 5.4^{\circ}$ and in Males $41.3^{\circ} \pm 5.9^{\circ}$ )

The ANOVA followed by post hoc Tukey test showed significant differences between the means of three groups (Table 1). The Pearson correlation showed significant negative correlation between ANB and Beta value indicting an increase in Beta angle with decrease in ANB angle and vice versa. (Table 2). Results showed Beta angle to be a reliable predictor of sagittal relationships with slight differences in mean values from those originally reported by Baik owing to different craniofacial features. There was no statistically significant difference in mean value between two genders.(Table 3 ) 
Table 1. Tukey test

\begin{tabular}{|l|l|l|l|l|}
\hline GROUP & \multirow{2}{*}{$\mathrm{N}$} & \multicolumn{3}{|l|}{} \\
\cline { 3 - 5 } & & 1 & 2 & 3 \\
\hline CLASS II & 46 & 25.0870 & & \\
\hline CLASS I & 22 & & 30.9545 & \\
\hline CLASS III & 22 & & & 40.2727 \\
\hline Sig. & & 1.000 & 1.000 & 1.000 \\
\hline
\end{tabular}

Table 2. Spearman Correlations

\begin{tabular}{|l|l|l|l|}
\hline \multicolumn{2}{|c|}{} & Beta & ANB \\
\hline \multirow{4}{*}{ Beta } & $\begin{array}{l}\text { Pearson } \\
\text { Correlation }\end{array}$ & 1 & $-.843^{\star \star}$ \\
\cline { 2 - 4 } & Sig. (2-tailed) & & .000 \\
\cline { 2 - 4 } & $\mathrm{N}$ & 90 & 90 \\
\hline \multirow{4}{*}{ ANB } & $\begin{array}{l}\text { Pearson } \\
\text { Correlation }\end{array}$ & $-.843^{\star *}$ & 1 \\
\cline { 2 - 4 } & Sig. (2-tailed) & .000 & \\
\cline { 2 - 4 } & $\mathrm{N}$ & 90 & 90 \\
\hline
\end{tabular}

Table 3. Mean values of Beta angle (in degrees)

\begin{tabular}{|l|l|l|l|}
\hline & \multicolumn{3}{|c|}{ CLASS } \\
\hline & I & II & III \\
\hline Females & 31.6 & 25.03 & 39.41 \\
\hline Males & 29.7 & 25.11 & 41.3 \\
\hline Mean (S.D.) & $30.9(3.4)$ & $25.0(3.6)$ & $40.2(5.6)$ \\
\hline
\end{tabular}

\section{DISCUSSION}

Accurate classification and treatment planning relies on correct diagnosis of skeletal and dental relationships. While there are many values and measurements devised for the purpose, we should keep in mind their inherent problems. Despite the number of linear and angular measurements present, no value is without a shortcoming $^{13}$. Analysis and measurements like ANB angle and Wit's appraisal are most commonly used to assess sagittal dysplasia. Problems in identification of landmarks as well as reference points which might change, renders the measurements less accurate and thus diagnosis less accurate. ANB angle given by Riedel presents problems when Nasion point (used as reference) undergoes change in its position. Also the length of cranial base may lead to a change ANB angle. Along with this ANB angle tends be unstable in case of rotations of jaw points. Witt's appraisal by
Jacobson appears to be an easy alternate to counter these problems as eliminating Nasion point in its measurement. Although it is considered as relatively better choice of analysis, but Witt's appraisal has its own problems. Wit's appraisal involves drawing of occlusal plane and thus an incorrect tracing of functional occlusal plane may lead to a faulty measurement. Problems such as open bite which causes two distinct occlusal planes presents problems of identification and drawing of correct occlusal plane. Mixed dentition cases, patients with asymmetries and canting of occlusal are other examples of cases which makes Wit's appraisal a troublesome choice.

Measurements based on palatal plane have also been introduced by some authors ${ }^{14}$. A high variability in its inclination has made it difficult to establish norms and mean values. Beta angle seems to be free of such issues as it is not taken by points and planes used in above mentioned analyses. Another point in favour of this angle is that due to its configuration it is not effected by rotations of jaws. In spite of all this there seems to be little yet resolvable issues of its own. Locating condyle is itself a rather challenging task. But a radiograph of higher quality is supposed to solve this problem. Another drawback being that this angle does not point toward the jaw at fault resulting in a faulty A-P relationship. Nevertheless along with other cephalometric measurements used this angle can surely help clinician to reach the conclusion fairly early and more accurately. Correct values measurements used for diagnosis and classification of sagittal dysplasia are key towards proper classification and planning of orthodontic problems. Beta angle appears to be a valuable tool in this regard. Every population has its own morphological differences in their craniofacial structures, so it will be erroneous to assume that one value calculated for one population will or can be used for a different population group. Assuming this the value of Beta angle was measured in our setting. The reason of conducting this study was to determine if or not this angle can be used for patients presenting in Orthodontic department Nishtar Institute of Dentistry Multan. Study showed significantly important statistical results rendering Beta angle a choice of measurement for anteroposterior skeletal dysplasia. Although statistically insignificant, our values appear to be slightly from those presented by Baik. For our population mean values of Beta angle are; for class I was $30.9^{\circ} \pm 3.4^{\circ}$ for class II was $25.08^{\circ} \pm$ $3.6^{\circ}$ and for class III was $40.2^{\circ} \pm 5.6^{\circ}$.

There appears to statistically insignificant gender differences in calculated mean values of Beta angle. There is also no statistically significant differences in mean values of those reported by Baik and between patients presenting in Nishtar Institute of Dentistry Multan Pakistan. 


\section{CONCLUSION}

ANB angle and Witt's appraisal although being used widely are susceptible to inherent difficulties leading to faulty diagnosis. Beta angle is reliable method for assessing and classifying sagittal skeletal discrepancies. For patients presenting for orthodontic treatment in Nishtar Institute of Dentistry Multan
Pakistan , mean values of Beta angle are; for class | $30.9^{\circ} \pm 3.4^{\circ}$ for class II $25.08^{\circ} \pm 3.6^{\circ}$ and for class III $40.2^{\circ} \pm 5.6^{\circ}$.

\section{Conflict of interest: None}

\section{OJN}

\section{REFERENCES}

1. Downs WB. Variations in facial relationships: their significance in treatment and prognosis. American journal of orthodontics. 1948 Oct 1;34(10):812-40

2. Riedel RA. Esthetics and its relation to orthodontic therapy. The Angle Orthodontist. 1950 Jul;20(3):168-78.

3. Riedel RA. An analysis of dentofacial relationships. American Journal of Orthodontics. 1957 Feb 1;43(2):103-19.

4. Binder RE. The geometry of cephalometrics. Journal of Clinical Orthodontics . 1979 April 13:258-63.

5. Taylor CM. Changes in the relationship of nasion, point A, and point B and the effect upon ANB. American journal of orthodontics. 1969 Aug 1;56(2):143-63.

6. Hussels W, Nanda RS. Analysis of factors affecting angle ANB. American journal of orthodontics. 1984 May 1;85(5):41 1-23.

7. Jacobson A. The "Wits" appraisal of jaw disharmony. American Journal of Orthodontics and Dentofacial Orthopedics. 1975 Feb 1;67(2):125-38.

8. Jacobson A. Update on the Wits appraisal. The Angle Orthodontist. 1988 Jul;58(3):205-19.

9. Haynes S, Chau MN. The reproducibility and repeatability of the Wits analysis. American Journal of Orthodontics and Dentofacial Orthopedics. 1995 Jun 1;107(6):640-7.

10. Rushton R, Cohen AM, Linney AD. The relationship and reproducibility of angle ANB and the Wits appraisal. British journal of orthodontics. 1991 Aug 1;18(3):225-31.

11. Baik CY, Ververidou M. A new approach of assessing sagittal discrepancies: the Beta angle. American journal of orthodontics and dentofacial orthopedics. 2004 Jul 1;126(1):100-5.

12. Hamdan AM, Rock WP. Cephalometric norms in an Arabic population. Journal of Orthodontics. 2001 Dec;28(4):297-300.

13. Moyers RE, Bookstein FL, Guire KE. The concept of pattern in craniofacial growth. American Journal of Orthodontics and Dentofacial Orthopedics. 1979 Aug 1;76(2):136-48.

14. Nanda RS, Merill RM. Cephalometric assessment of sagittal relationship between maxilla and mandible. American Journal of orthodontics and Dentofacial orthopedics. 1994 Apr 1;105(4):328-44. 